PNL-10558

UC-350

\title{
Flow Meter Evaluation for U.S. Navy Public Works Center San Diego, California
}

\author{
W. D. Chvála, Jr \\ K. L. McMordie \\ R. F. Szydlowski
}

June 1995

Prepared for

the Federal Energy Management Program

U.S. Department of Energy

under Contract DE-AC06-76RLO 1830

Pacific Northwest Laboratory

Richland, Washington 99352 


\section{DISCLAIMER}

This report was prepared as an account of work sponsored by an agency of the United States Government. Neither the United States Government nor any agency thereof, nor any of their employees, make any warranty, express or implied, or assumes any legal liability or responsibility for the accuracy, completeness, or usefulness of any information, apparatus, product, or process disclosed, or represents that its use would not infringe privately owned rights. Reference herein to any specific commercial product, process, or service by trade name, trademark, manufacturer, or otherwise does not necessarily constitute or imply its endorsement, recommendation, or favoring by the United States Government or any agency thereof. The views and opinions of authors expressed herein do not necessarily state or reflect those of the United States Government or any agency thereof. 


\section{DISCLAIMER}

Portions of this document may be illegible in electronic image products. Images are produced from the best available original document. 


\section{Preface}

The goal of the U.S. Department of Energy Federal Energy Management Program (FEMP) is to facilitate energy efficiency improvements at federal facilities. This is accomplished by a balanced program of technology development, facility assessment, and use of cost-sharing procurement mechanisms. Technology development focuses on the tools, software, and procedures used to identify and evaluate energy efficiency technologies and improvements. For facility assessment, FEMP provides metering equipment and trained analysts to federal agencies exhibiting a commitment to improve energy use efficiency. To assist in procurement of energy efficiency measures, FEMP helps federal agencies devise and implement performance contracting and utility demand-side management strategies.

Pacific Northwest Laboratory (PNL), ${ }^{(a)}$ supports the FEMP mission of energy systems modernization. Under this charter, the Laboratory and its contractors work with federal facility energy managers to assess and implement energy efficiency improvements at federal facilities nationwide.

(a) Pacific Northwest Laboratory is a multiprogram laboratory operated for the U.S. Department of Energy under contract DE-AC06-76RLO 1830 by Battelle Memorial Institute. 



\section{Summary}

The U.S. Navy Public Works Center San Diego (PWCSD) was concerned about the accuracy of various flow meters on steam and compressed air lines serving Naval facilities in San Diego, California. The flow meters had experienced various inconsistencies that had not been resolved prior to July 1993.

Pacific Northwest Laboratory, Richland, Washington, evaluated the operation of 10 out of 79 steam and compressed air flow meters at PWCSD. The evaluation was limited to analysis of historical information and review of existing operating procedures. On-site investigation of the flow meters was limited to external observations of the flow-sensing equipment and a check of the flow computer program. PNL did not remove installed sensing equipment (i.e., flow meters or temperature or pressure sensors) to evaluate existing condition or check calibration.

Although many of the flow meter errors can be traced to improperly normalized readings and to meters improperly compensated for temperature and pressure, lack of regular maintenance, including proper calibration, was evidenced throughout this study. A strict calibration schedule should be established for all steam and air flow meters, including calibration of the temperature sensor, pressure sensor, and flow turbine. It is recommended that the most crucial flow meters (such as the 10 evaluated in this study) be calibrated yearly. The remaining 69 flow meters could be placed on a staggered, biyearly calibration schedule.

Calibration should be done by qualified personnel only. Improper calibration is often worse than no calibration at all. An outside firm is recommended to be contracted with to perform all maintenance and calibration on flow meters at the Naval facilities. Use of an outside firm would better facilitate regular, reliable calibration while removing liability for damaged parts. 



\section{Acknowledgments}

The authors gratefully acknowledge the assistance of Ruby Shimabukuro, David Rylaarsdam, Jesse Drummer, and Ray Miller of San Diego Gas and Electric; John Thomas, Norm Groth, Don Nicholas, and Ed Brakebill of Public Works Center San Diego; and Bob Miner, Steve Zawadzki, Johnny Johnston, Sandy Pusey, and David Winn of Southwest Division, Naval Facilities Command. 



\section{Contents}

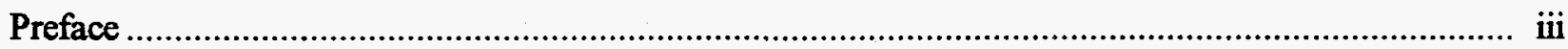

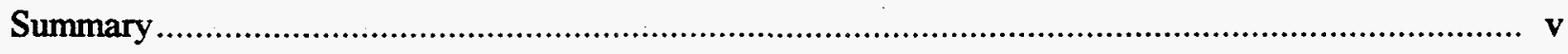

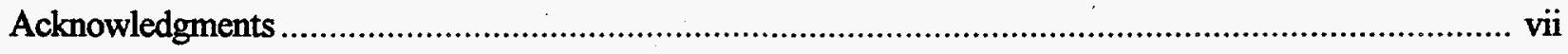

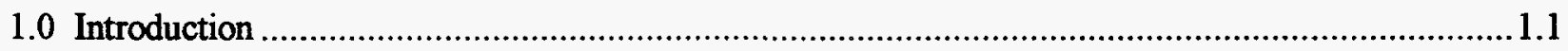

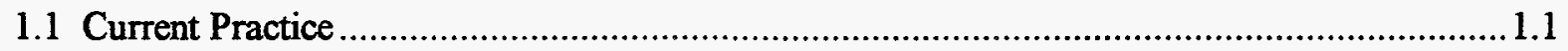

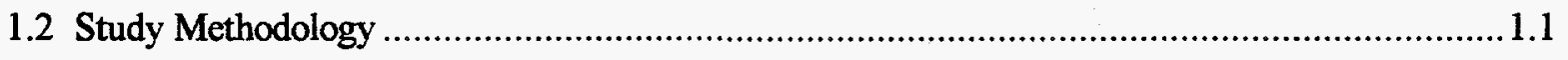

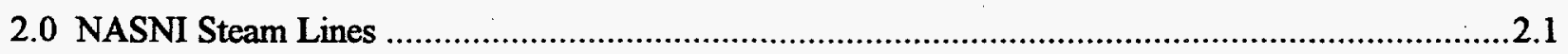

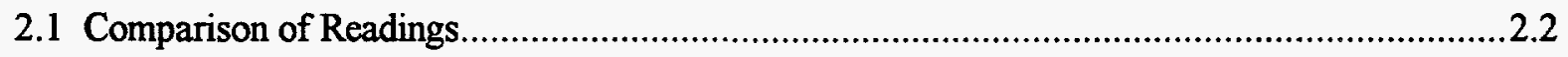

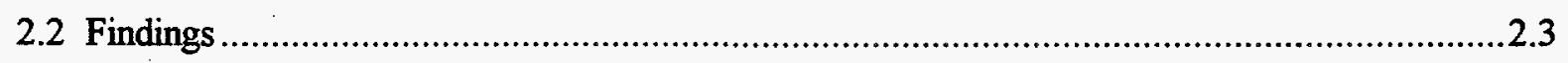

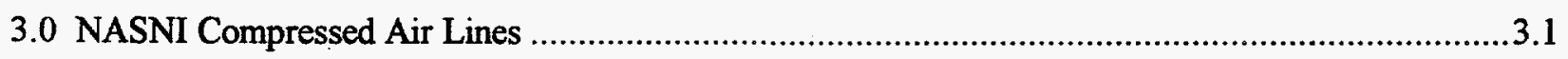

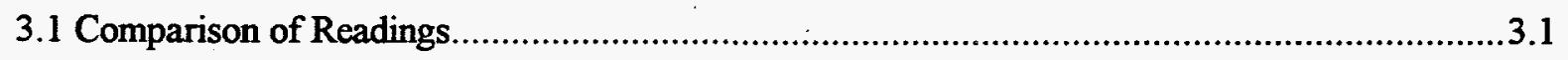

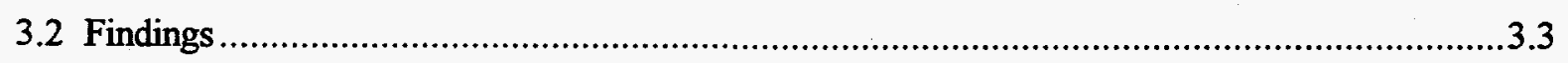

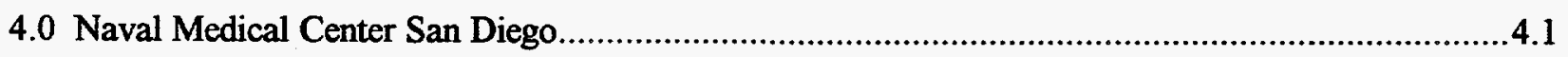

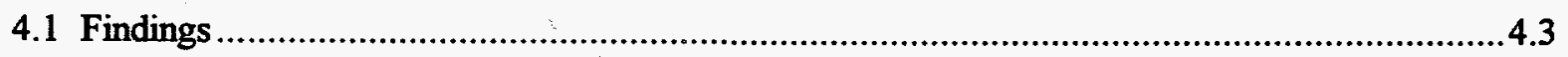

5.0 NEX Laundry Facility Steam Line ...................................................................................

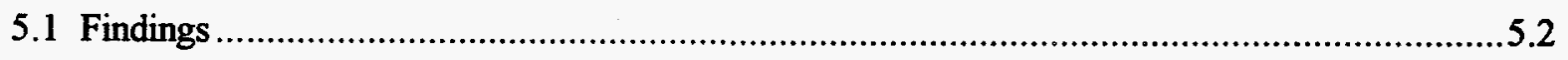

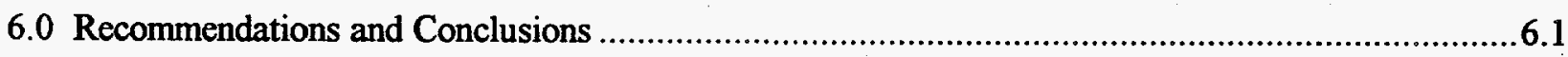

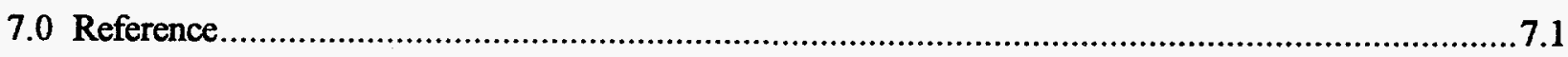




\section{Figures}

2.1 Flow Meter Installation on NASNI Steam Lines 2.1

2.2 Flow Meter Readings on NASNI Steam Lines, November 1989 through July 1993

2.3 Flow Meter Readings on NASNI Steam Lines, August 1992 through July 1993 2.3

3.1 Location of Flow Meters on NASNI Compressed Air Lines 3.1

3.2 Flow Meter Readings on NASNI Compressed Air Lines, October 1989 through July 1993 3.2

3.3 Flow Meter Readings on NASNI Compressed Air Lines, August 1992 through July 1993 3.2

4.1 Flow Meter Readings on Steam Lines at Naval Medical Center San Diego, April 1990 through October 1992

5.1 Flow Meter Readings on Steam Lines at NEX Laundry Facility, San Diego, October 1992 through March 1993 


\section{Abbreviations and Acronyms}

$\begin{array}{ll}{ }^{\circ} \mathrm{F} & \text { degrees Fahrenheit } \\ \mathrm{AEI} & \text { Applied Energy Incorporated } \\ \mathrm{Btu} & \text { British thermal unit(s) } \\ \mathrm{d} & \text { day } \\ \text { EMCO } & \text { Engineering Measurements Company } \\ \mathrm{ft} & \text { foot (feet) } \\ \mathrm{ft}^{3} & \text { cubic foot (feet) } \\ \text { h } & \text { hour } \\ \mathrm{kW} & \text { kilowatt } \\ \mathrm{lb} & \text { pound (U.S.) } \\ \text { MBtu } & \text { million British thermal unit(s) } \\ \text { mo } & \text { month(s) } \\ \text { MUR } & \text { Metered Utility Report } \\ \text { MUSE } & \text { Mobile Utilities Support Equipment } \\ \text { NARDAC } & \text { Navy Regional Data Automation Center } \\ \text { NASNI } & \text { Naval Air Station, North Island } \\ \text { NEX } & \text { Navy Exchange } \\ \text { PNL } & \text { Pacific Northwest Laboratory } \\ \text { PWCSD } & \text { Public Works Center San Diego } \\ \text { QF } & \text { Qualified Facility } \\ \text { SDG\&E } & \text { San Diego Gas and Electric } \\ \text { UCS } & \text { Utility Control System } \\ \text { USN } & \text { United States Navy } \\ & \end{array}$




\subsection{Introduction}

The U.S. Navy (USN) Public Works Center San Diego (PWCSD) was concerned about the accuracy of flow meters on steam and compressed air lines serving Naval facilities in San Diego, California. The various inconsistencies experienced prior to July 1993 have yet to be resolved. The PWCSD requested that Pacific Northwest Laboratory (PNL), Richland, Washington, evaluate the operation of the most important and most suspect flow meters on steam and compressed air lines. This task was conducted as Amendment 2 under the Navy Regional Data Automation Center (NARDAC) San Diego Cogeneration Project.

\subsection{Current Practice}

There are 79 flow meters located on steam and compressed air lines throughout the Naval facili-ties in San Diego. These meters track flow and record data for billing reimbursable customers-customers that reimburse the Base for the amount of energy used.

The PWCSD and, in some cases, its subcontractors are responsible for reading the meters. Steam and compressed air consumption are recorded in two distinct manners. Therefore, understanding how the meters are read is important to understanding some of the problems experienced in reconciling the meterreading data.

Traditionally, meters have been read manually by PWCSD staff once each month and reported in a Meter Utility Report (MUR). MURs only depict total consumption since the last meter reading. Because the meters reported in the MURs are read once each month on different days, it is difficult to compare readings between meters without the proper normalization.

Starting in February 1993, the PWCSD connected its computerized Utility Control System (UCS) to flow meters throughout the Base. The UCS electronically records steam and compressed air data at fixed intervals during the day and calculates a daily total at midnight. Consumption can be analyzed on a daily basis to accurately characterize the usage of steam and compressed air. An additional benefit is that a precise number of days can be compared between meters without data normalization concerns.

\subsection{Study Methodology}

The PNL team began its evaluation on July 20, 1993. Preliminary information was gathered via telephone and facsimile machine, and a low-level analysis was performed on the historical meter-reading records. The initial baseline analysis sought to familiarize PNL with the available data and determine if there were any obvious trends or inconsistencies in the recorded data. The PNL team 
conducted an on-site visit of the Naval facilities in San Diego on August 11 and 12, 1993 to examine the flow meters, conduct interviews with equipment operators, and collect additional metering data.

The PNL investigation was limited to analysis of historical information and review of existing operating procedures. The on-site investigation of the flow meters consisted of external observations of the flowsensing equipment and a check of the flow computer program. PNL did not remove installed sensing equipment (i.e., flow meters or temperature or pressure sensors) to evaluate existing condition or check calibration.

The PNL investigation focused on the following 10 flow meters:

- three flow meters on steam lines at the Naval Air Station, North Island (NASNI) - the Applied Energy Incorporated (AEI) billing meter, the USN's Station distribution line meter, and the USN's Quaywall distribution line meter (discussed in Section 2.0)

- three flow meters on compressed air lines at NASNI-the Plant (total production) meter, the USN's Station distribution line meter, and the USN's Quaywall distribution line meter (discussed in Section 3.0)

- three flow meters on steam lines on the cogeneration heat recovery boilers at Naval Medical Center San Diego (discussed in Section 4.0)

- one flow meter on a steam line at the Navy Exchange (NEX) laundry facility, Building B-226, located at the Naval Training Center (discussed in Section 5.0).

From the findings drawn from the evaluations in each of the aforementioned sections, recommendations for routine maintenance are given in Section 6.0. The reference cited in the text is given in Section 7.0. 


\subsection{NASNI Steam Lines}

Steam is supplied to the Base by the AEI cogeneration facility located adjacent to the Base near the compressed air facility, Building 653. AEI installed and maintains a pressure- and temperaturecompensated flow-nozzle meter to measure the steam supplied to the USN complex. AEI's central monitoring and control computer reads the flow meter electronically every 6 minutes and calculates a daily total at midnight.

The AEI-supplied steam connects with two major USN distribution lines, Station and Quaywall. PWCSD installed and maintains pressure-compensated Engineering Measurements Company (EMCO) insertion turbine flow meters on each distribution line. The PWCSD's flow meters are pressure, but not temperature, compensated. Both EMCO flow meters are located within $300 \mathrm{ft}$ of the AEI flow meter (Figure 2.1).

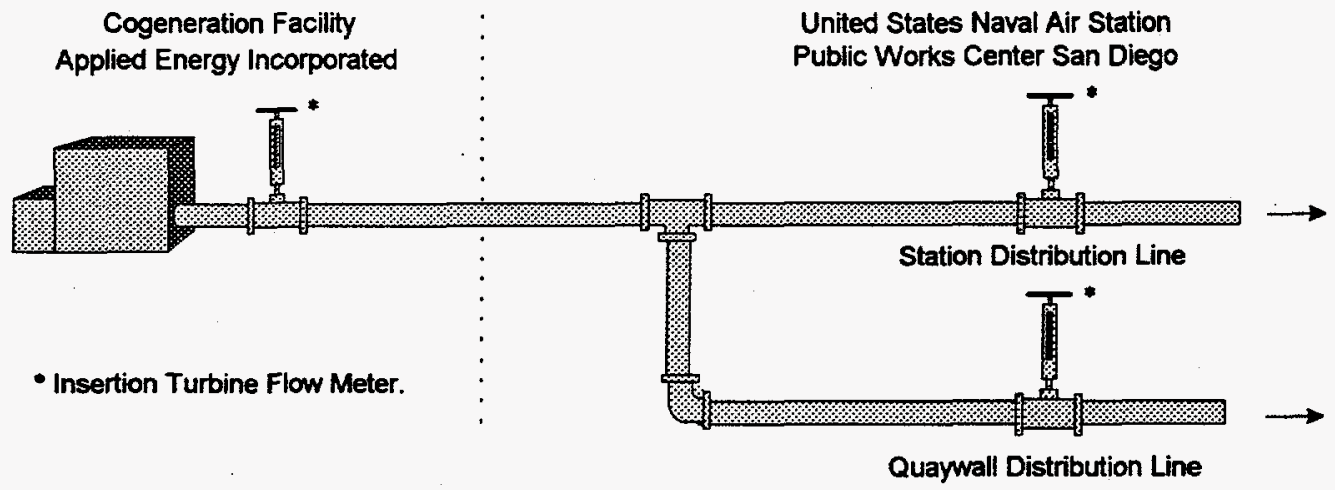

Figure 2.1. Flow Meter Installation on NASNI Steam Lines

The PWCSD and AEI meters are read manually by PWCSD staff once each month and reported in three separate MURs for the Station, Quaywall, and AEI meters. For the MUR, PWCSD staff obtain the AEI meter value by manually reading an AEI computer-displayed total-this value is not electronically recorded. AEI also maintains its own computerized historical log of USN steam consumption.

These manual readings are conducted on different days each month, and the USN and AEI readings may occur on different days in the same month. Therefore, an accurate comparison requires that all the readings be normalized to a common time period. Because the manual readings do not have a time of day associated with them, the normalization is limited to an average day during a particular month.

The PWCSD also reads the Station and Quaywall flow computers connected to the EMCO flow meters electronically through the UCS at 15-minute intervals. These readings are summed at midnight each day to 
calculate daily totals. This procedure was implemented to parallel AEI's metering procedures to standardize comparisons.

\subsection{Comparison of Readings}

Figure 2.2 shows the historical MUR data of the Quaywall, Station, and AEI data. On average, 54,902 MBtus/mo are supplied to the Base by AEI. The original analysis conducted by PWCSD revealed significant differences between AEI's invoiced meter readings and the USN's MUR data for the Station and Quaywall meters. These errors ranged from $-29 \%$ to $11 \%$ (standard deviation $=15.9 \%$ ) for October 1991 through August 1992. However, this comparison was not valid because the data in the MURs were not normalized to uniform monthly time periods. Readings were taken on different days at different times, producing monthly readings with months of different lengths. Accurate comparison requires that the readings from both meters encompass the same time period.

After the UCS was installed, meter readings could be reported in complete months, rather than simply the time between meter readings. The differences between the AEI's invoiced meter readings reported and the USN's MUR data for the Station and Quaywall flow meters were reduced to $-7.8 \%$ to $14.5 \%$ (standard deviation $=6.1 \%$ ) for August 1992 through February 1993 .

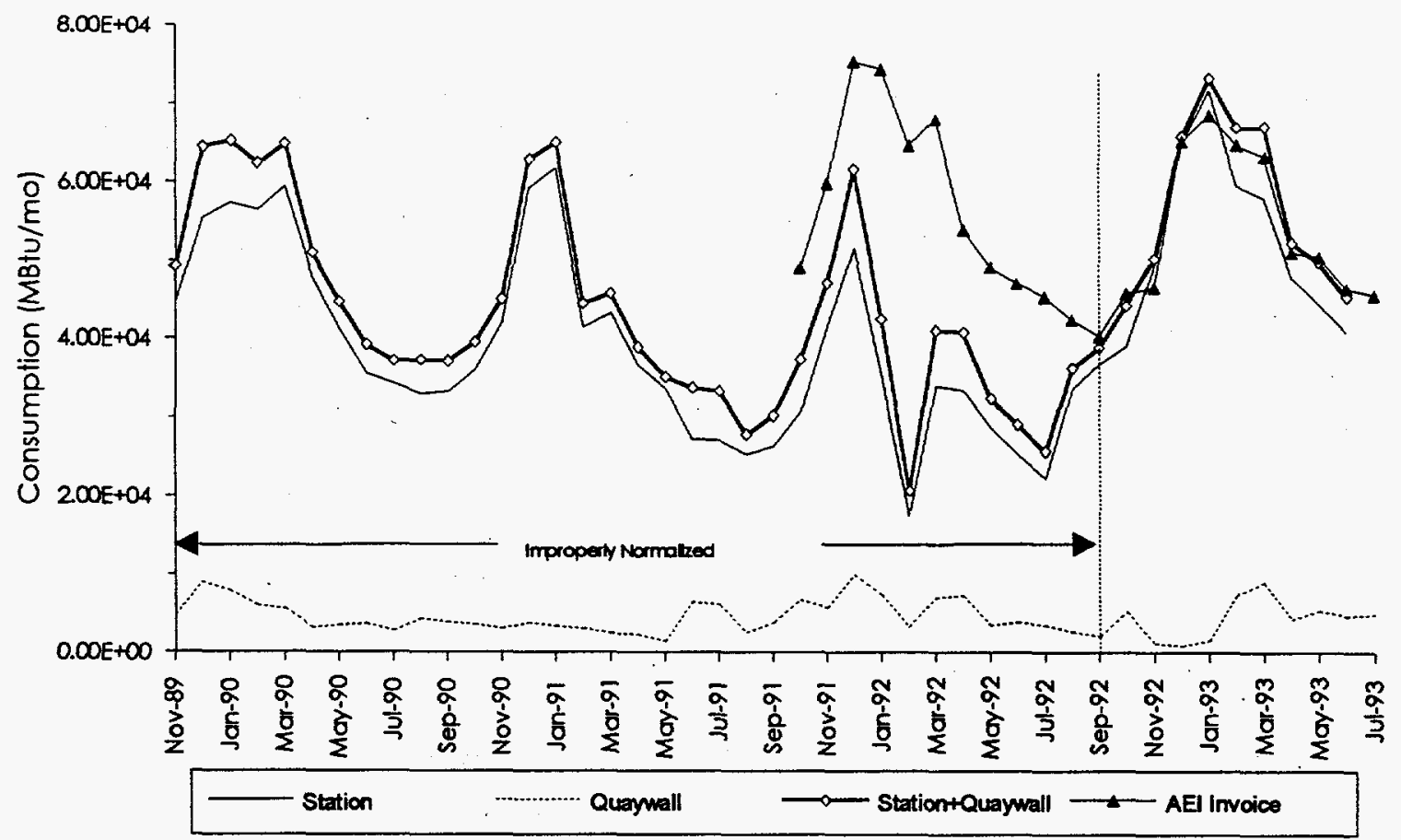

Figure 2.2. Flow Meter Readings on NASNI Steam Lines, November 1989 through July 1993 
A comparison of monthly data from the PWCSD's new UCS and AEI's invoices during February through July 1993 revealed differences of only $-7.5 \%$ to $3.3 \%$ (standard deviation $=3.6 \%$ ). The main reason for improved comparison between USN and AEI meter readings was the installation of the UCS after August 1992. The UCS reads the EMCO flow computers and synchronizes the monthly totals to the same day and time as the AEI invoice. Figure 2.3 shows more recent data of the total steam consumption as reported by the MURs, UCS, and AEI invoice. Figure 2.3 also shows the percent difference between the MURs and UCS compared to the AEI invoices during this same time period.

\subsection{Findings}

During PNL's site visit, the team met with PWCSD staff to gain a better understanding of the procedures used to determine monthly consumption. The PNL team reviewed and verified that the physical installation and the flow computer programming were correct. The calibration of the flow meters was not checked. The following is a summary of PNL's findings for the NASNI flow meters:

- An inspection of the AEI billing meter revealed that it was being operated properly. The on-site review of AEI's flow meter and computerized monitoring system identified no problems.

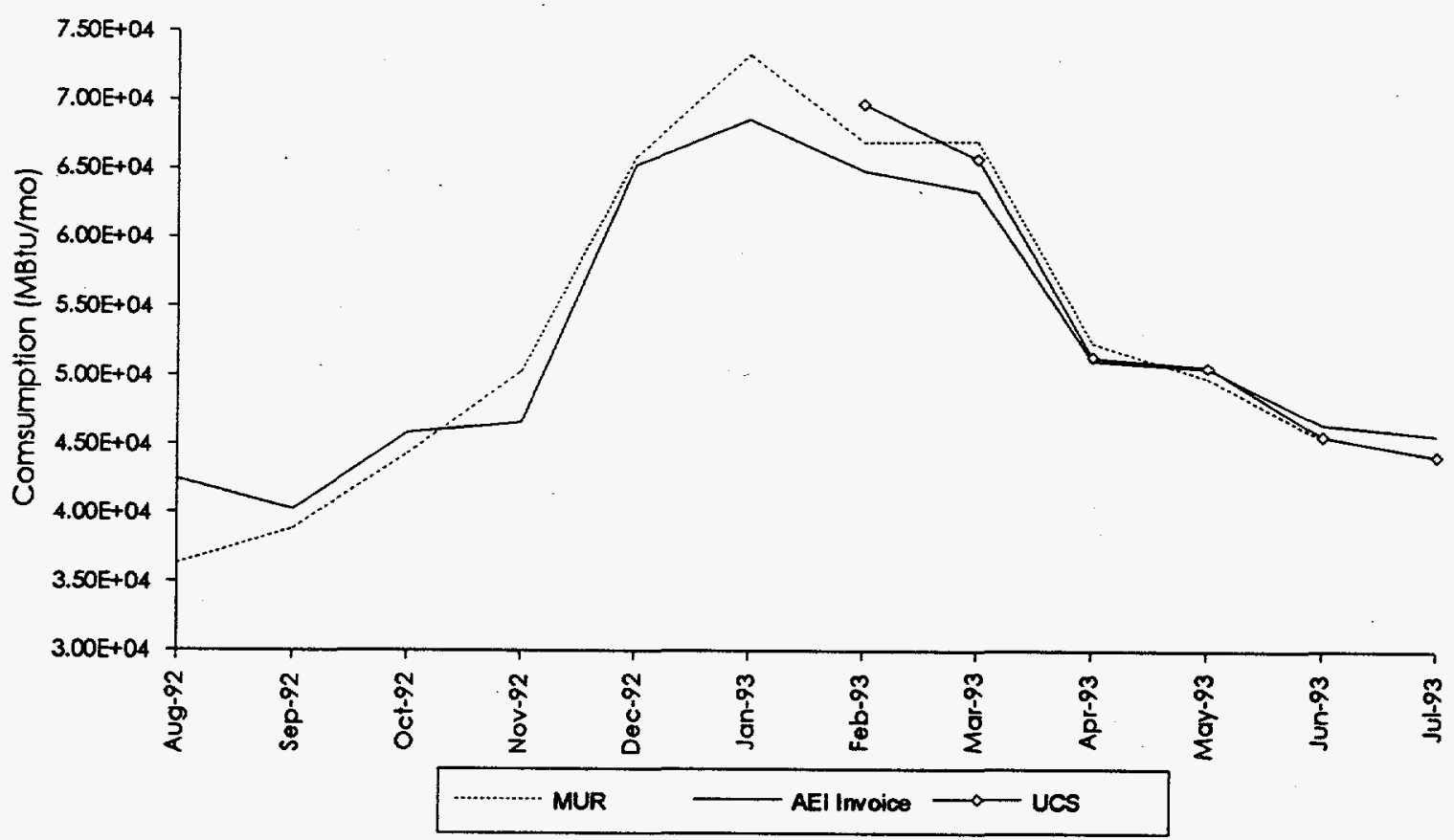

Figure 2.3. Flow Meter Readings on NASNI Steam Lines, August 1992 through July 1993 
- No major problems were found in the installation or operation of the flow meters on AEI, Station, and Quaywall steam lines. With the UCS recording of the flow meters on the Station and Quaywall steam lines, the manual meter reading problems are eliminated and the comparison between AEI and USN values is reasonable.

- The temperature sensor installed at the Station flow meter was not working. The sensor problem was discovered after the last temperature- and pressure-sensor calibration, which was conducted on June 16,1993 . The insertion turbines were not calibrated nor replaced during the calibration of the temperature and pressure sensors. PWCSD staff indicated that the turbines have not been calibrated on an annual basis. Although the inoperable temperature sensor does not have any effect on the flow rate calculation (because temperature compensation is not used), it does provide insight into the problems associated with lack of proper maintenance of meters at the Base. PWCSD's Station and Quaywall meters are compensated for pressure only, which is correct only if the steam is saturated. With some superheat, as would be expected from the AEI's cogeneration facility, both pressure and temperature compensation are required for accurate readings.

- Finally, errors may be introduced by poor calibration and maintenance of the flow meters on steam lines. This issue will be discussed in more detail in Section 6.0. 


\subsection{NASNI Compressed Air Lines}

Compressed air for NASNI is provided by five air compressors located in Building 653. PWCSD uses three pressure- and temperature-compensated EMCO insertion turbine flow meters to measure the volume of compressed air. One flow meter measures flow through the Plant (total plant output) and the other two record flow to the Station and Quaywall distribution lines (Figure 3.1).

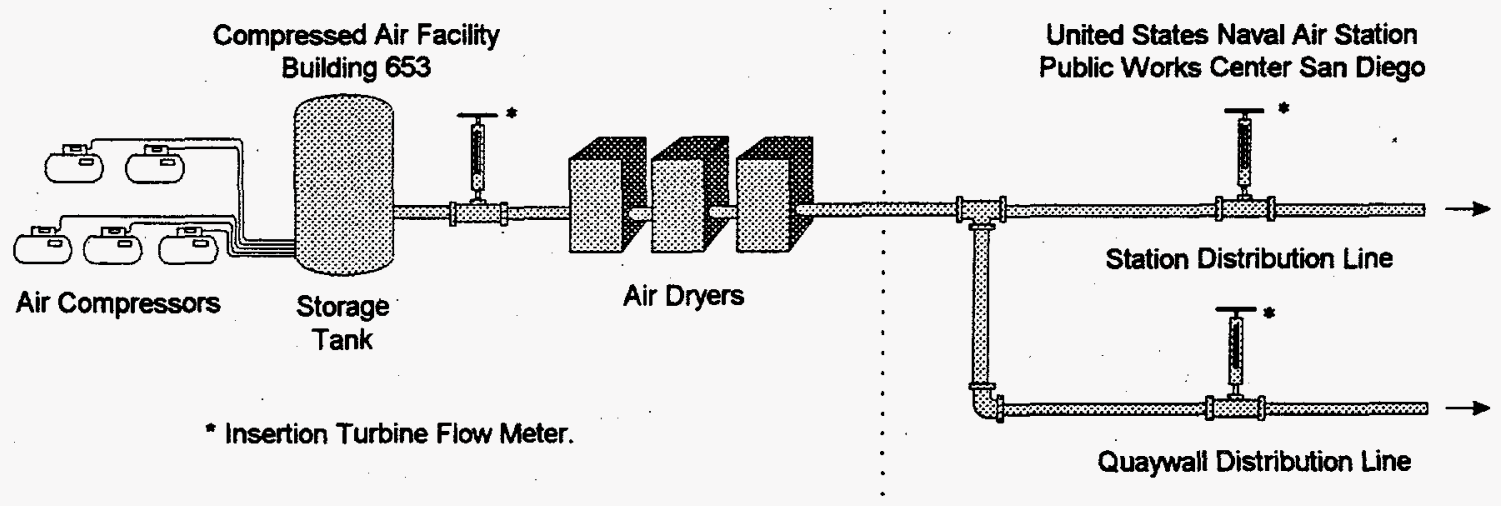

Figure 3.1. Location of Flow Meters on NASNI Compressed Air Lines

The flow meters on the compressed air lines are read manually by PWCSD staff once each month and reported in three separate MURs for the Plant total, Station, and Quaywall meters. Starting in February 1993, the PWCSD connected its UCS to the flow computers and began electronically reading the flow meters at 15-minute intervals. These readings are summed at midnight each day to calculate daily totals. A monthly total is then obtained from the daily totals, producing a total monthly consumption for each meter.

\subsection{Comparison of Readings}

The PNL team compared MUR data for the sum of the Station and Quaywall meters with the Plant meter for the period August 1992 through July 1993. The errors were $-5.8 \%$ to $8.9 \%$ (standard deviation = $3.8 \%$ ). A second comparison, using MUR data for the sum of the Station and Quaywall meters and the UCS-recorded Plant meter data during February through July 1993, resulted in errors of $-5.4 \%$ to $10.3 \%$ (standard deviation $=5.48 \%$ ). Figure 3.2 shows historical MUR data for the total Plant output, Station distribution line, and Quaywall distribution line since October 1989. 


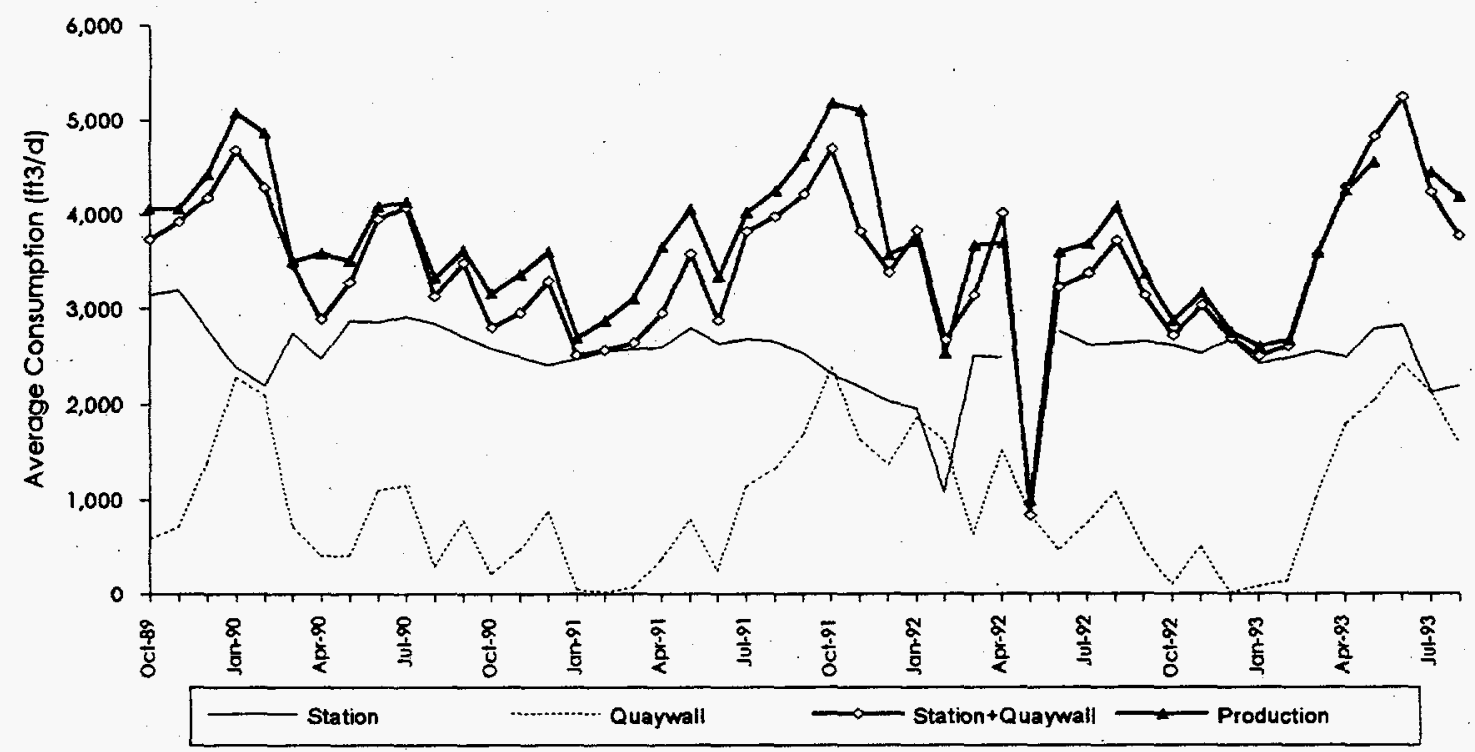

Figure 3.2. Flow Meter Readings on NASNI Compressed Air Lines, October 1989 through July 1993

Figure 3.3 shows more recent compressed air data for the Plant, Station, and Quaywall flow meters from the MURs and UCS. Figure 3.3 also shows a comparison of the sum of the flow meters on the Station and Quaywall distribution lines with the MUR and UCS values of the Plant flow meter.

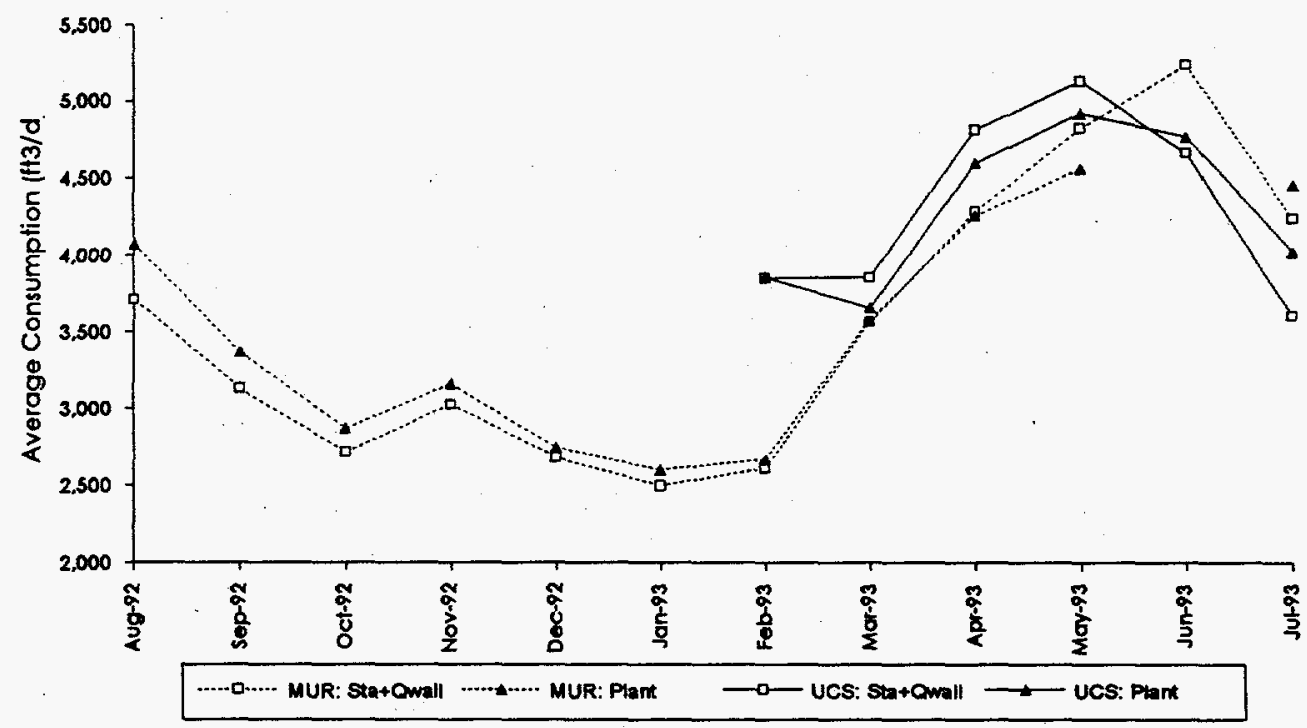

Figure 3.3. Flow Meter Readings on NASNI Compressed Air Lines, August 1992 through July 1993 


\subsection{Findings}

The PNL team reviewed and verified that the physical installation and flow computer programming. were correct. The calibration of the flow meters was not checked. An accurate comparison of Plant total versus the Station and Quaywall distribution lines using MUR data cannot be conducted because of improper normalization.

The following is a summary of PNL's findings of the flow meters on the NASNI compressed air system:

- With the UCS recording of the flow meter readings on compressed air lines, the manual meter-reading problems are eliminated and the comparison between Plant and sum of Station and Quaywall is within reasonable limits.

- The pressure sensor at the Quaywall meter and the temperature sensor at the Station meter were inoperative. These sensor problems were discovered by the PWCSD after the last temperature- and pressure-sensor calibration, which was conducted on June 16, 1993, but were not replaced. The flowsensing turbines were not calibrated nor replaced at the same time, and PWCSD staff indicated that the turbines are not replaced on an annual basis. The lack of operative sensors directly affects the temperature and pressure compensation required to accurately measure the compressed air flow.

- Moisture is removed from the compressed air by three refrigerated air dryers located between the Plant meter and the Station and Quaywall distribution line meters. As moisture is removed from the compressed air, the mass flow rate is reduced. This may play a role in the difference between the sum of the Station and Quaywall meter readings and the Plant's meter reading. Ideally, the dryers should be located upstream of the Plant total meter.

- Finally, errors may be introduced by poor calibration and maintenance of the flow meters on steam lines. This issue will be discussed in more detail in Section 6.0. 


\subsection{Naval Medical Center San Diego}

The Naval Medical Center San Diego produces electricity from a cogeneration facility powered by three solar combustion gas turbines each rated at $800 \mathrm{~kW}$ total output. Heat is recovered from the gas turbine exhaust through three heat recovery boilers (each rated at $6040 \mathrm{lb} / \mathrm{h}$ ) to produce steam for the hospital. PWCSD is concerned with the resulting output from the heat recovery boilers because the meters have been measuring relatively low steam generation. These cogeneration units have been operating since 1986 .

Previous to March 5, 1993, the steam supplied by each heat recovery boiler was measured using in-line, differential-pressure, orifice-plate flow meters. The steam flow rates were sufficient to permit the medical center to be classified as a Qualified Facility (QF) under the Federal Energy. Regulatory Commission and San Diego Gas and Electric (SDG\&E) rules. This status allows the medical center to purchase natural gas at a reduced rate under a QF rate of $\$ 0.304 /$ therm for the summer season and $\$ 0.309 /$ therm for the winter season.

After March 5, 1993, three EMCO insertion turbine flow meters and flow computers were installed to replace the orifice-plate flow meter system. The steam flow rates measured by the turbine flow meters were $71 \%$ of those previously measured by the orifice-plate flow meters. If these lower steam flow rates are accurate, PWCSD is concerned that the medical center will lose its QF status, therefore being charged a noncogeneration rate for gas of $\$ 0.352 /$ therm for summer and $\$ 0.366 /$ therm for winter.

The PWCSD staff indicated that the steam flow calculation procedure used with the original orificeplate flow meters may have been incorrect, resulting in higher than actual flow readings. It is also suspect that the strip chart recorder was scaled incorrectly and the flow readings were interpreted incorrectly off the strip chart recorder. Unfortunately, all of the original orifice-plate flow meter calculation equipment has been removed, thus preventing any verification of previous calculation methodology.

Figure 4.1 shows historical data for steam production by the heat recovery boilers. There is no main flow meter, so the sum of the individual flow meters could not be compared to an overall total as a cross check. The PNL team reviewed and verified that the physical installation and the flow computer programming were appropriate. The calibration of the flow meters was not checked.

Although poor calibration and operation of the orifice-plate flow meters appear to have caused higher than actual readings in the past, the operation of the gas turbines appears to have changed since the new flow meters were installed. The gas turbines, which are rated at a full load output of $800 \mathrm{~kW}$, were only operating at $600 \mathrm{~kW}$ during the PNL visit ( $600 \mathrm{~kW}$ is only $75 \%$ of total load). The steam output of the heat recovery boilers, which are rated at $6040 \mathrm{lb} / \mathrm{h}$, were only operating at 


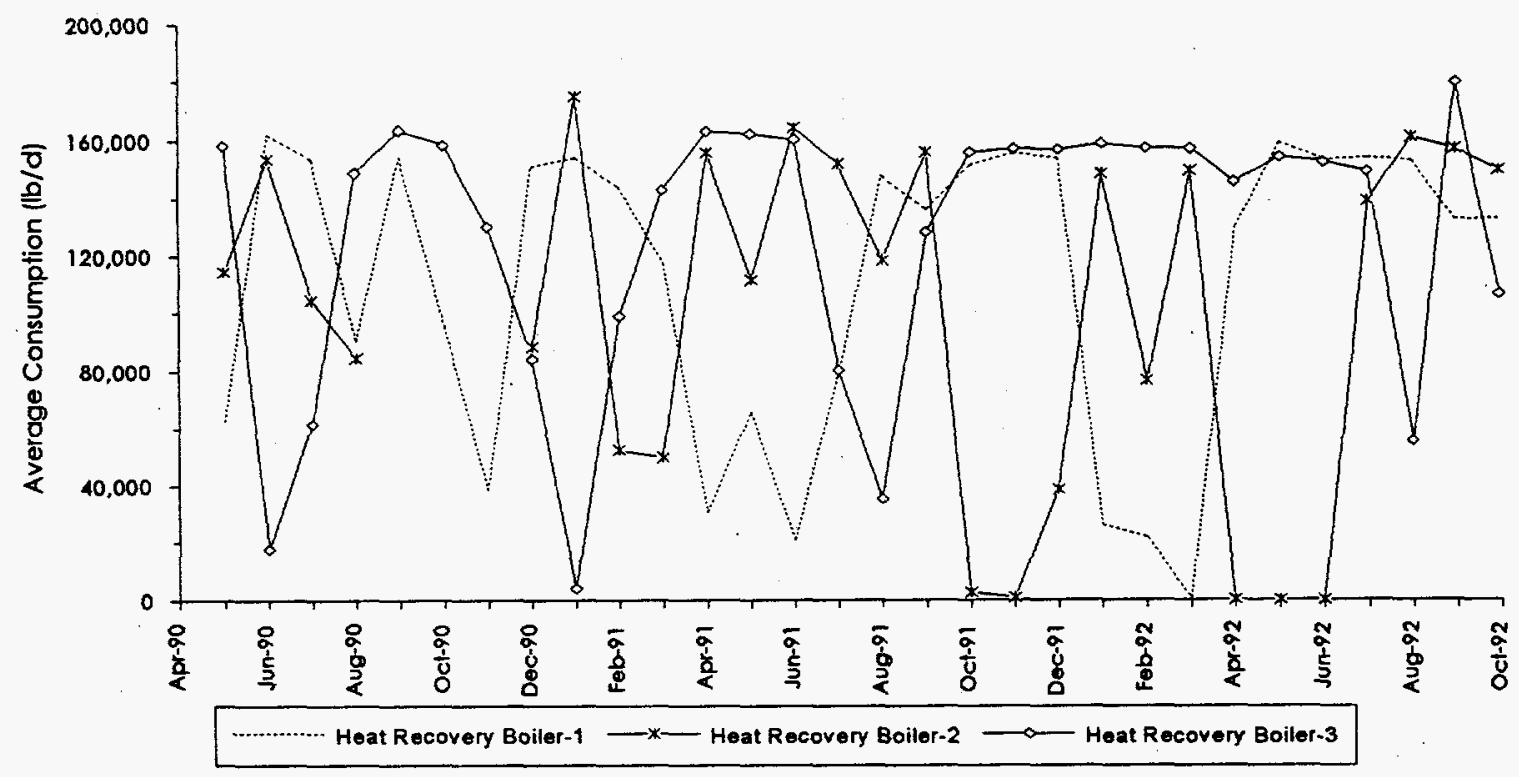

Figure 4.1. Flow Meter Readings on Steam Lines at Naval Medical Center San Diego, April 1990 through October 1992

approximately $4000 \mathrm{lb} / \mathrm{h}$ or $66 \%$ load. The effectiveness and efficiency of heat recovery boilers are typically reduced at partial loads resulting from the reduced flow of hot exhaust gas from the gas turbines. The reason the gas turbines were operating at $600 \mathrm{~kW}$ is unknown and beyond the scope of this evaluation.

The PNL team attempted, with little success, to measure the temperature of the exhaust gases departing the heat recovery boilers. The exhaust stacks are not equipped with temperature sensors, such as permanently installed thermocouples, or even access points for spot temperature measurements. Because no access to the exhaust gas was provided, temperature measurements were made on the surface of the exhaust stacks for units 1 and 3 . The exhaust stack surface temperatures were $525^{\circ} \mathrm{F}$ and $400^{\circ} \mathrm{F}$ for units 1 and 3 , respectively.

Surface temperatures are not an accurate representation of mean exhaust temperature, so the usefulness of this information is minimal. They are, however, higher than expected. A true exhaust gas temperature would need to be measured and compared to the original heat recovery boiler design. An exhaust stack temperature higher than design may indicate a fouled or inefficient heat exchanger. Fouling could result from soot buildup on the gas side of the boiler tubes or scale build-up on the water side of the boiler tubes. The heat recovery boilers should be examined for fouling, soot, and scale during their next scheduled inspection. 


\subsection{Findings}

The PNL team determined that the calculation of steam flow rate from the original orifice-plate flow meters was incorrect and that the new turbine flow meters and flow computers are operating correctly. The following is a summary of PNL's findings for the medical center's heat recovery boilers:

- The PWCSD should reanalyze the heat recovery boiler steam production based on the actual electric production to determine if there is a real problem. If the facility's QF status is in danger, production of electricity should be increased to increase steam output to required levels. PWCSD needs to access the use of the cogeneration facility to determine the optimal level of output and what is most economically efficient.

- Each heat recovery boiler exhaust stack should be equipped with a temperature sensor. Stack temperatures should be taken as part of the routine boiler logs. A slow rise in boiler exhaust stack temperature over time will indicate the buildup of soot or scale and a reduction in the effectiveness of the heat recovery boilers.

- In the future, errors will be introduced if the flow meters are not calibrated and maintained correctly. This issue will be discussed in more detail in Section 6.0. 


\subsection{NEX Laundry Facility Steam Line}

Steam is normally supplied to the NEX laundry facility, Building B-226, from the central steam distribution system. However, during October 1992 through April 1993, a Mobile Utility Services Equipment (MUSE) portable, natural-gas-fired boiler was installed to provide steam for the NEX laundry facility during repair work on the central steam distribution system. Throughout the period before, during, and after the installation of the portable boiler, the same EMCO in-line vortex shedding flow meter was used to meter the total steam consumption of the NEX laundry facility.

Throughout this time period, the same SDG\&E billing meter was used to measure the natural gas consumption supplied to a USN distribution point at Farragut and Rosencran Streets. From this point, the natural gas is distributed to a least 16 end users. Although most of the end users are reimbursable customers, some are separately metered by PWCSD and others are estimated. PWCSD bills the reimbursable customers based on metered data, where available, or estimated values. The portable boiler at the NEX laundry facility was connected to the natural gas distribution system, but was not separately metered.

During operation of the portable boiler, NEX laundry facility management noticed that, according to the laundry flow meter, the energy supplied to the laundry facility was greater than the energy in all the natural gas being supplied by SDG\&E to the USN's distribution point. Because the portable boiler was only one of several end users connected to that distribution point, the portable boiler's gas consumption should have been much less than the SDG\&E's billing value. Unfortunately, the portable boiler's natural gas consumption was never directly metered.

The PWCSD conducted a series of investigations in an attempt to identify the source of the discrepancy.

- The gas consumption for the portable boiler was estimated by subtracting estimates for each of the end users on the gas distribution system from the SDG\&E-metered value. This showed that approximately $75 \%$ of the total SDG\&E-supplied gas was being consumed by the portable boiler. With this gas consumption and assuming an $\mathbf{8 0 \%}$ efficiency, the portable boiler's potential steam production was approximately one half of the metered steam production.

- The steam consumption of the NEX laundry facility was estimated by developing an estimate of steam demand for each component in the facility. The results indicated that the facility should be consuming much less steam than was being metered.

- The PWCSD asked SDG\&E to recalibrate their gas meter. The original gas meter calibration was within $2 \%$ of the new calibration-which is well within specifications. 
The PWCSD ultimately credited the NEX laundry facility for the difference between the metered steam consumption and the maximum potential steam production based on natural gas consumption. An explanation for the difference was never identified, and the NEX laundry facility is now charged for steam based on the same flow meter. Figure 5.1 shows SDG\&E's historical data of gas consumption and PWCSD's estimated steam production.

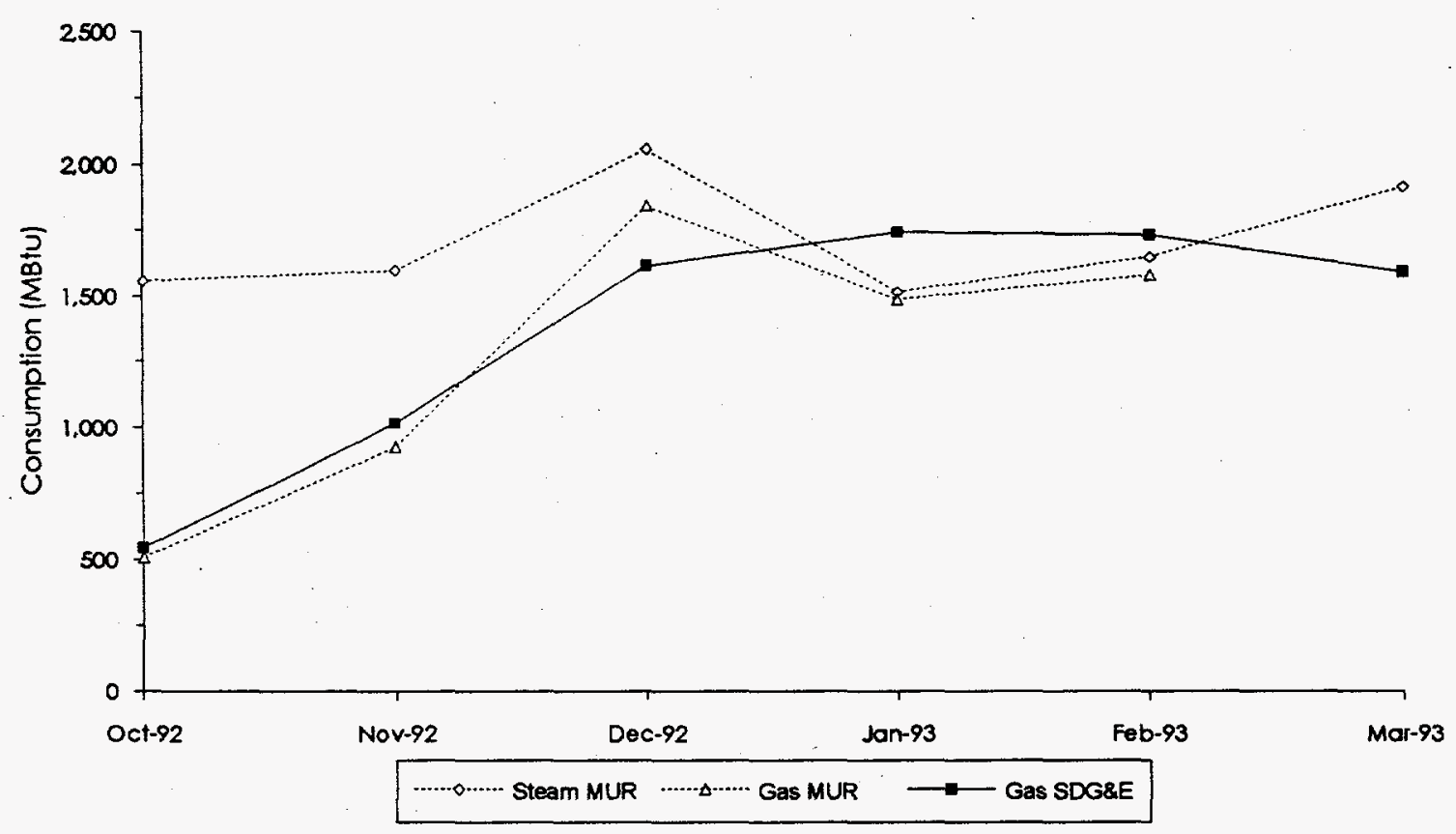

Figure 5.1. Flow Meter Readings on Steam Lines at NEX Laundry Facility, October 1992 through March 1993

\subsection{Findings}

The PNL team visited the NEX laundry facility, reanalyzed the steam and gas meter data, and verified that the PWCSD's original calculation technique was correct. PNL could not verify the individual end user gas consumption data and the NEX laundry facility steam consumption estimate, but errors in these two values would have little impact on the overall problem.

The PNL team reviewed and verified that the physical installation and the flow computer programming were appropriate. The calibration of the flow meters was not checked. Based on external observations, no problems were identified with the existing vortex flow meter and flow computer. Because the MUSE boiler was removed in April 1993, investigation was limited to review of historical metering records. 
One reason to suspect the accuracy of the flow meter is the potential vibration from irregular steam flow. The steam demand from steam presses in the laundry facility will be high for short time durations. These rapid flow-rate pulses may cause the vortex shedding detector to sense false vortices (through steam pressure pulses or induced pipe vibration) and record an increased and incorrect flow rate.

The vortex shedding flow meter should be temporarily replaced with a calibrated turbine flow meter. The turbine flow meter can use the existing flow computer with minimal reprogramming. A turbine flow meter is recommended as the replacement because it is inherently less susceptible to pulsing flow rates and pipe vibration. An orifice-plate flow nozzle could also be used as a replacement flow meter. Subsequent analyses of the NEX laundry facility's steam consumption before and after the flow meter switch and the vortex flow meter's calibration results should provide conclusive evidence as to the accuracy of the existing vortex shedding flow meter.

Finally, a schedule for calibration and routine maintenance should be established and adhered to. This issue will be discussed in greater detail in Section 6.0. 


\subsection{Recommendations and Conclusions}

In addition to the specific findings reported in each section, some general recommendations were developed that are applicable to all flow meters.

Although many of the flow meter errors noted in this study can be traced to improperly normalized readings, to meters improperly compensated for temperature and pressure, and to other errors separate from the meter itself, it is likely that improper calibration of the flow meters is responsible for additional errors. In spite of the fact that inspection of flow turbines was beyond the scope of this study, conversations with PWCSD staff indicated a lack of regular calibration and replacement of damaged or defective flow turbines.

A routine calibration schedule should be established and performed on all steam and air flow meters, including calibration of the temperature, pressure, and flow turbine sensors. The calibration schedule can be on an adaptive or fixed schedule. The adaptive schedule would be based on the rate of sensor calibration change over time, resulting in a calibration frequency that is appropriate and cost effective. This could be accomplished by programming the UCS to send a warning for flow meters that are beginning to drift beyond a predetermined range. The fixed schedule requires that each meter be calibrated after a fixed period of time regardless of its operating characteristics. Whichever schedule is chosen, it should include each of the 79 flow meters located at the USN facilities.

Conversations with technical support personnel at EMCO, the manufacturer of some of the flow meters on the Base, indicate that while operating conditions influence how frequently flow meters require calibration, they recommend flow meters should be calibrated at least once per year. Flow meters in critical areas or operating under harsh conditions should be calibrated more frequently.

Calibration involves removing the in-place turbine from the line and replacing it with a spare flow turbine. If the physical condition of the flow turbine has deteriorated, it should be replaced. The flow turbine is then sent to the manufacturer or another facility with the proper equipment to calibrate flow turbines. The temperature and pressure sensors must also be removed and inspected. Any defective sensors should be replaced at that time. Finally, when the turbine is returned, the new calibration is fed into the flow computer and the computer itself checked for problems.

Calibration should be done by qualified personnel only. Improper calibration is often worse than no calibration at all. PNL recommends that an outside firm be contracted to perform all maintenance and calibration of flow meters at the Base. Military installations have traditionally experienced difficulty in establishing comprehensive operations and maintenance programs because of insufficient staffing, insufficient funding, lack of experienced personnel, high turnover rates, among other things (Szydlowski et al. 1994). Use of an outside firm would better facilitate regular, reliable calibration while removing liability from PWCSD personnel for damaged parts. Part of the cost might be paid for by eliminating the 
redundant manual meter readings that are less accurate than the UCS. Manual readings could be used only in emergency situations.

The ideal calibration schedule would be to calibrate all meters on at least an annual basis. If it is impossible to calibrate each of the 79 flow meters yearly, a prioritized list of important meters could be calibrated yearly, while the rest are placed on a biyearly calibration schedule. A reasonable calibration schedule would be to require that the 10 meters evaluated in this study be calibrated yearly. In addition, if meter readings in the UCS deviate from an expected range, additional calibrations would be required. The remaining meters would be calibrated biyearly, half one year and half the next. The specific details of the maintenance schedule need to be worked out with the group responsible for the calibration of the flow meters.

By implementing and adhering to a definite routine maintenance and calibration program, many of the problems experienced can be avoided. Whether the work is performed by an outside firm or by Base personnel, it is crucial that the work be competently performed on a regular basis. 


\subsection{Reference}

Szydlowski, R. F., J. S. Schliesing, and D. W. Winiarski. 1994. "No Maintenance-No Energy Efficiency." In Proceedings of the $17^{\text {th }}$ World Energy Engineering Congress, $4^{\text {th }}$ Environmental Technology Expo, pp. 619-628. Association of Energy Engineers, Atlanta, Georgia. 


\section{Distribution}

No. of

Copies

Offsite

2 DOE/Office of Scientific and Technical Information

6 U:S. Department of Energy

Federal Energy Management Program 1000 Independence Avenue SW

Washington, DC 20585

Attn: K. Dean Devine, EE-44 (2)

M. Ginsberg, EE-44

L . Harris (2), EE-44

V. Petrolatti, EE-44

J. Ashley

NAVFAC Code 135A

200 Stoval Street

Alexandria, VA 22332-2300

F. Beason

U.S. Air Force

Civil Engineering Support Agency

HQ AFCESA/ENM

139 Barnes Drive

Tyndall AFB, FL 32403-5319

M. Carr

U.S. Department of Defense

Office of Secretary of Defense

DASD (L) EP

The Pentagon

Washington, DC 20301-8000

J. Heller

Naval Facilities Engineering

Service Center

Code 111E2

Port Hueneme, CA 93043-5014
No. of

Copies

Offsite

6 R. Miner

Southwest Division, Naval

Facilities Engineering Command

Code 1632RM

1220 Pacific Highway

San Diego, CA 92132-5910

6 J. Thomas

U.S. Navy Public Works

Center, San Diego

PWC Code 650, Box 368113

2730 McKeen Street, Suite 1

San Diego, CA 92136-5113

$3 \quad$ K. L. McMordie

100 East River Ranch Road

Snowmass, CO 81654

Onsite

DOE Richland Operations Office

J. K. Schmitz

K8-50

29

Pacific Northwest Laboratory

D. M. Carroll (9)

K5-08

W. D. Chvála, Jr. (6)

K5-08

L. K. Fastabend (2)

K5-06

D. J. Hostick (3)

K8-17

S. A. Parker (3)

K5-08

W. F. Sandusky III

K5-08

Technical Report Files (5) 